\title{
The Swedish Adoption Twin Study of Aging: An Update
}

\author{
N.L. Pedersen ${ }^{1,4}$, G.E. McClearn'1,2, R. Plomin ${ }^{1,2}$, J.R. Nesselroade ${ }^{1,3}$, S. \\ Berg $^{6}$, U. DeFaire ${ }^{5}$ \\ ${ }^{1}$ Center for Developmental and Health Genetics; ${ }^{2}$ Intercollege Graduate Program in Genetics, \\ and ${ }^{3}$ Center for Developmental and Health Methodology, The Pennsylvania State University, \\ University Park, PA, USA; ${ }^{4}$ Department of Environmental Hygiene, The Karolinska Institute, \\ Stockholm, ${ }^{5}$ Department of Internal Medicine, Karolinska Hospital, Stockholm, and ${ }^{6} /$ institute \\ for Gerontology, Jönköping, Sweden
}

\begin{abstract}
The Swedish Adoption/Twin Study of Aging (SATSA) is a longitudinal program of research in gerontological genetics which is currently in its fifth year. The base population is comprised of 351 pairs of twins reared apart and 407 matched control pairs of twins reared together who responded to a questionnaire (Q1) in 1984. Two additional stages of SATSA have recently been completed: a longitudinal follow-up questionnaire mailed out in 1987 (Q2) and extensive in-person testing (IPT1) which included a health examination and cognitive battery. A second wave of IPT was started in January 1989. A summary of some of the major findings from Q1 and a description of IPT1 are reported.
\end{abstract}

Key words: Twins reared apart, Aging, Personality, Health, Cognition

\section{INTRODUCTION}

The value of samples of twins separated at an early age and reared apart for the study of genetic and environmental influences on behavior has long been recognized, but few such samples have been available [7]. At the Fourth International Congress on Twin Studies in London, 1983, three large samples were described: Bouchard and collaborators had then identified 44 pairs of monozygotic twins reared apart (MZA) and 25 pairs of dizygotic twins reared apart (DZA) mostly in North America [5]; Finnish investigators described results from 165 pairs of twins reared apart (TRA) from the populationbased Finnish Twin Registry [10]; and a third sample with 961 TRA pairs had been identified from the Swedish Twin Registry [14]. 
A program of research in gerontological genetics, known as the Swedish Adoption/Twin Study of Aging (SATSA), was begun in 1984. The base population includes the sample of TRA from the Swedish Twin Registry [6] and a control sample of twins reared together (TRT) which was matched on the basis of gender, age and county of birth. In July 1984, both members of 591 TRA pairs and one surviving member of 221 TRA pairs were alive. At the same time, 627 intact TRT pairs and 197 single-surviving TRT individuals were alive. The details of the sampling and testing procedures for the questionnaire portion of SATSA have been described earlier $[12,18,23]$. In the present report, we will briefly review the SATSA design, describe in detail the in-person testing and provide summaries of some of the analyses already performed.

\section{SAMPLE AND PROCEDURES}

SATSA is a longitudinal study with a three-year interval between measurement occasions. During each wave of testing, both mail-out questionnaire and in-person testing (IPT) components are included (Fig. 1). The first occasion began in October, 1984, with a two part mail-out questionnaire (Q1) sent to the 2,854 individuals alive in July 1984 . Responses to the first questionnaire (Q1a) were received from 2018 individuals. Questionnaire B (Q1b) was sent to all individuals who responded to Q1a, after an interval of about one week. A total of 1736 questionnaires was received. The distribution of the 758 intact pairs responding to Q1a and the 597 intact pairs responding to Q1b by rearing status and zygosity is reported in Table $1^{a}$. The questionnaires assessed physical and mental health status; selected personality dimensions; activities of daily living; healthrelated behaviors of smoking, alcohol consumption and legal drug use; early rearing environment and the adult working, family and social environments [12]. For the TRA subjects, circumstances of separation were also explored [17].

Q1 was followed by telephone cognitive testing of a subsample of 82 TRT and 114 TRA pairs (Table 1). The procedures and measures for this aspect of SATSA have been described by Nesselroade et al [13].

In-person testing (IPT) involved an interview, administration of cognitive tests and a health examination of a subset of the SATSA twins. All but 12 of the 548 pairs 50 years of age and older in which both had responded to Q1a were contacted by telephone to enlist participation. There was no effort made to select pairs on the basis of rearing status, zygosity or gender. Twins from another 12 pairs were solicited for participation in ancillary studies and not included in IPT. A total of 201 pairs were lost due to death

a SATSA manuscripts on Q1a data published prior to 1990 report that the number of individuals responding to Q1a was 2015 and the number of pair responses was 750, whereas the current paper lists 2018 individuals and 758 pairs. The discrepancy is due to clerical errors discovered after the Q1a data were analyzed. The errors include failure to enter data for 5 individuals who responded late and inclusion of 2 respondents who where not twins $(2015+5-2=2018)$. For 4 pairs the ID number of one twin was incorrectly entered, resulting in a failure to match members of the pair. Data for the new individuals and new pairs are not included in the Q1a analyses. Two individuals were incorrectly matched as a pair and included in the Q1a analyses. This is the only error of inclusion which would have affected the Q1a results. The final number of pairs responding to Q1a was $750+5+4-1=758$. 


\section{The Swedish Adoption/Twin Study of Aging}

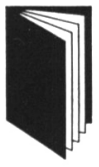

Q1

758 pairs (351 TRA)

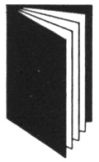

Q2

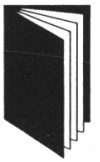

Q3

548 pairs (257 TRA)

\begin{tabular}{|l|l|l|l|l|l|l|l|}
\hline 1984 & 1985 & 1986 & 1987 & 1988 & 1989 & 1990 & 1991 \\
\hline
\end{tabular}
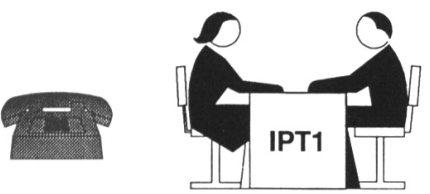

196 pairs

(114 TRA)
303 pairs

(147 TRA)

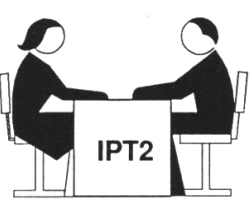

Fig. 1. Longitudinal design of the Swedish Adoption/Twin Study of Aging.

of one or both twins (68 pairs), illness of one or both twins ( 7 pairs), blindness ( 7 pairs), and refusal to participate (119 pairs). In 32 pairs, only one member was tested because the cotwin had died, become too ill, or refused to participate. Both members of 291 pairs 50 years of age or older and 12 pairs under 50 years were tested (Table 1). The distribution of individuals tested by age group and gender is presented in Table 2.

Table 1 - Number of pairs participating in the steps of SATSA, by zygosity and rearing status

\begin{tabular}{lrrrrrr}
\hline Group & Q1a & Q1b & Q2 & Telephone & IPT1 & Cognitive \\
\hline MZA & 99 & 83 & 72 & 34 & 46 & 59 \\
MZT & 166 & 136 & 127 & 35 & 67 & 93 \\
DZA & 238 & 182 & 178 & 76 & 100 & 114 \\
DZT & 221 & 175 & 155 & 46 & 89 & 117 \\
XZA & 14 & 8 & 7 & 4 & 1 & 1 \\
XZT & 20 & 13 & 9 & 1 & 0 & 0 \\
Total & 758 & 597 & 548 & 196 & 303 & 384 \\
\hline
\end{tabular}

Note: $\mathrm{MZ}=$ identical, $\mathrm{DZ}=$ fraternal, $\mathrm{XZ}=$ undetermined zygosity, $\mathrm{A}=$ reared apart, $\mathrm{T}=$ reared together. 
Table 2 - Distribution of twins in IPT1 by age at testing and gender

\begin{tabular}{lcc}
\hline Age group (yr) & Males & Females \\
\hline & & \\
$<50$ & 8 & 15 \\
$50-59$ & 44 & 74 \\
$60-69$ & 121 & 134 \\
$\geq 70$ & 65 & 145 \\
Total & 238 & 368 \\
\hline
\end{tabular}

Table 3 - Biomedical measures in the in-person testing phase of SATSA

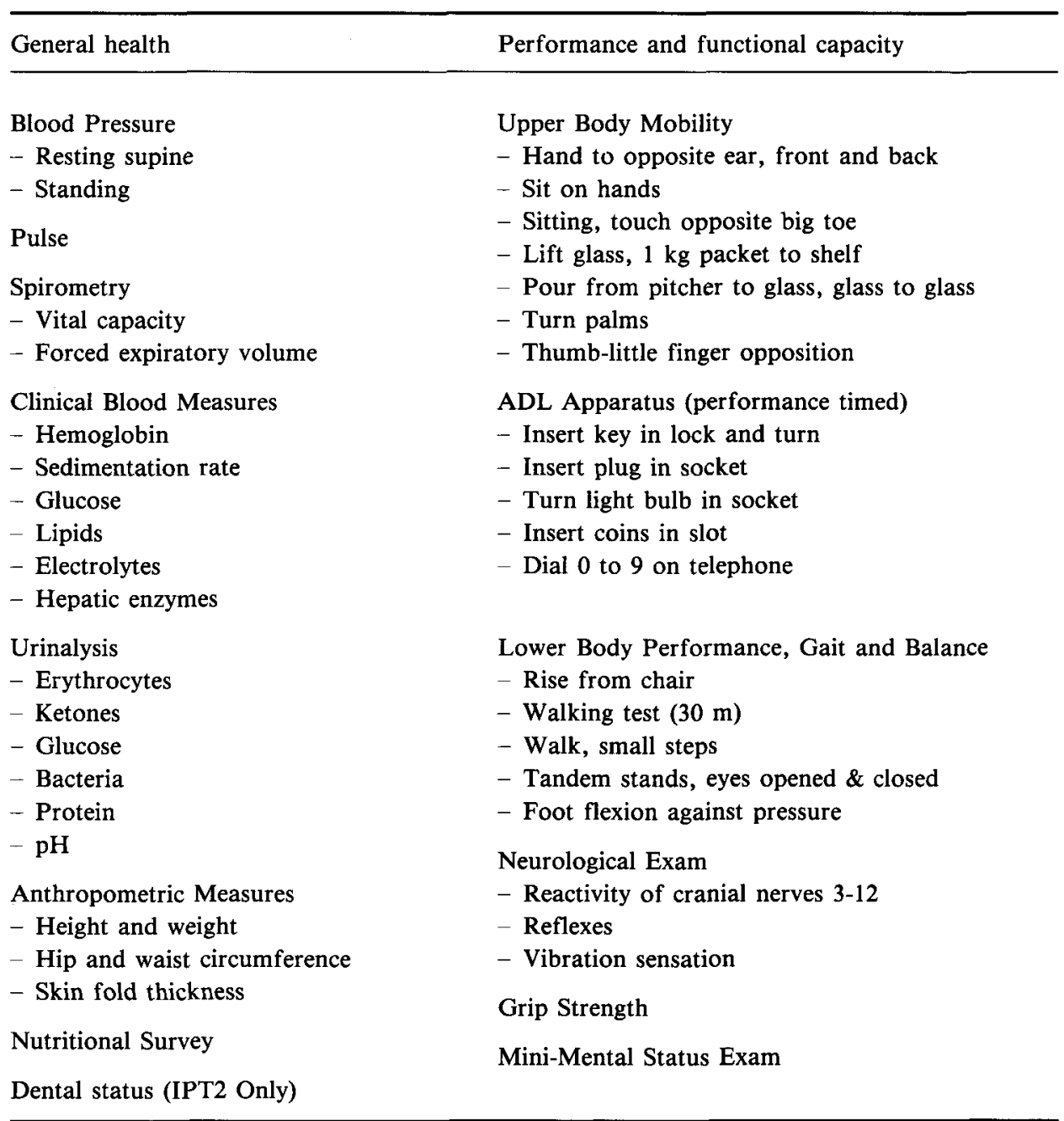


There were two major components of IPT: biomedical and cognitive assessment. The choice of measures was directed in part by concerns for maintaining comparability with other aging studies (especially Swedish studies), for minimizing time demands on the subjects and for ease in administration in remote sites. Fasting blood samples were drawn for later analysis of a wide range of clinical chemistries including lipids and for zygosity diagnosis. The biomedical portion of the battery (Table 3 ) was designed to assess general health status, with particular attention to measures which are sensitive to age changes and might therefore be useful biomarkers of aging [24]. For this reason, measures of lung function (vital capacity and forced expiratory volume), grip strength, and physical performance measures for upper and lower body functional capacity were included. Many of the performance measures were chosen on the basis of their ecological validity for measuring activities of daily living (eg, turn key in lock, pour glass of water). One series of tests was included to determine possible impairment of the cranial nerves. The extensive nutritional survey allows computation of quantity and frequency measures of several nutrients.

The cognitive battery was designed to represent the domains of crystallized and fluid intelligence and memory [13]. The battery (Table 4) included all of the tests used in the H-70 study of aging in Gothenburg, Sweden [1]. Additional measures of spatial ability and perceptual speed were included so that specific cognitive abilities, commonly analyzed in behavioral genetic research, would be represented. The structure of the cognitive battery is currently being analyzed.

The testing was administered by registered nurses. Because many older individuals prefer not to travel great distances, the nurses met the twins at a location close to the twins' home. For the most part, district nurses' offices, health-care schools, and longterm care clinics were used. In a few cases, the twins preferred to be tested in their homes. If both members of a pair lived in the same area, they were not encouraged to

Table 4 - Cognitive tests and domains in SATSA

\begin{tabular}{|c|c|c|}
\hline \multirow{2}{*}{ Test } & Domain & \multirow{2}{*}{ Specific cognitive ability } \\
\hline & Crystallized/Fluid & \\
\hline Information & Crystallized & Verbal \\
\hline Synonyms ${ }^{a}$ & Crystallized & Verbal \\
\hline Analogies & Fluid \& crystallized & Verbal, reasoning \\
\hline Figure logic $a$ & Fluid & Spatial, reasoning \\
\hline Block design ${ }^{a}$ & Fluid & Spatial \\
\hline Card rotation & & Spatial \\
\hline Digit span $(F \& B)^{a}$ & & Memory \\
\hline Picture memory $^{a}$ & & Memory \\
\hline Names and faces & & Memory \\
\hline Digit symbol & & Perceptual speed \\
\hline Figure identification ${ }^{a}$ & & Perceptual speed \\
\hline
\end{tabular}

${ }^{a}$ Test included in H-70 study of aging in Sweden [1]. 
be tested on the same day. When possible, different nurses tested the members of a pair. Most individuals $(67 \%)$ were tested in the mornings. They were instructed to collect a morning urine sample which they brought to the testing site. Subjects arrived fasted since the evening before. (If they were tested during the afternoon or evening, they were told not to eat anything for at least 6 hours prior to testing.) After blood samples were drawn, the subjects were given a light breakfast. The order of the testing session, which took 4 hours on the average, is described in Fig. 2. IPT1 was started in November 1985 and completed in November 1988.

\section{SATSA In-Person Testing Session}

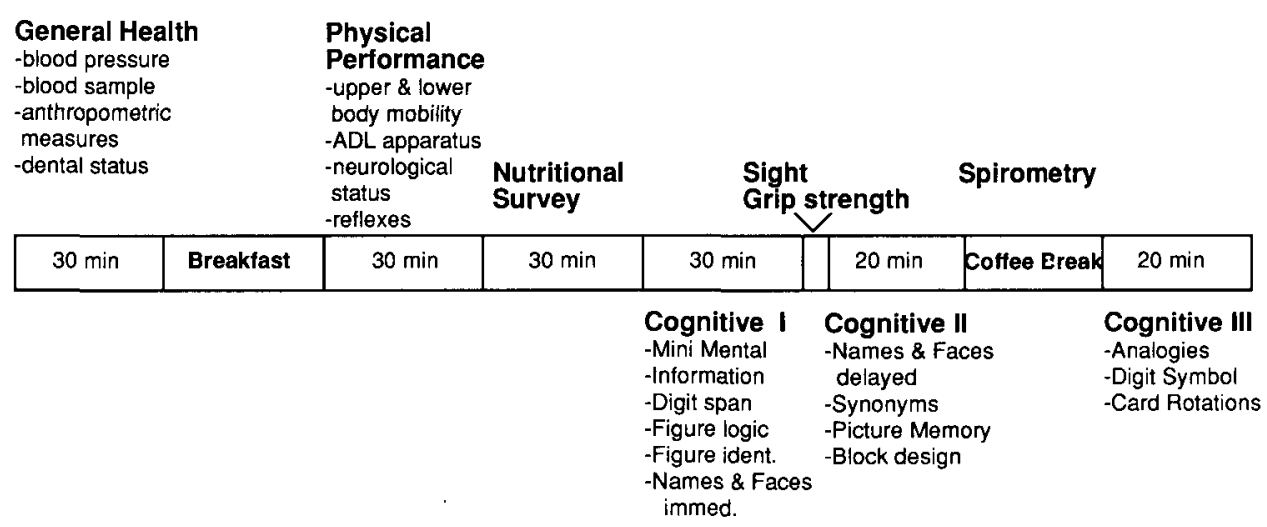

Fig. 2. Design of in-person testing session in the Swedish Adoption/Twin Study of Aging.

A subsample of the pairs under 50 years of age in which both members responded to Q1a and Q1b were recruited for participation in a study of " biopsychological vulnerability" at the Department of Psychiatry of the Karolinska Hospital [25]. These twins filled out extensive personality inventories, participated in computerized neuropsychological testing, and were administered the same cognitive battery as that which the IPT twins were given. Thus, the sample of SATSA twins for which there are cognitive data available is actually 384 pairs (Table 1) ranging in age from 28 to 85 .

The second wave of SATSA testing began with a mail-out questionnaire (Q2) sent in October 1987 to all surviving individuals who had not requested discontinuation of further participation ( $N=2581$ ). The segments of $Q 1$ for which longitudinal assessment were not relevant, such as early rearing environment, were eliminated from Q2. Responses were received from 1637 individuals. Eighty-three of these twins had not responded to Q1. Both members of 548 pairs responded to Q2 (Table 1).

The second wave of IPT testing (IPT2) began in January 1989 and will continue until 
November 1991. IPT2 is the same as IPT1 with the addition of dental status assessment and additional measures of gait and balance. Q3, which is identical to Q2, is sent to participants in IPT2 one week prior to the scheduled date for in-person testing.

\section{Zygosity Determination}

Zygosity diagnoses were first made on the basis of physical similarity. This procedure was described in detail by McClearn et al [12]. Sufficient blood for zygosity assessment was collected from 368 of the 384 pairs participating in any form of in-person testing. Serum proteins (Gc, $\mathrm{Hp}, \mathrm{BF}, \mathrm{PLG}, \mathrm{Gm}, \mathrm{Kml}$ and Gci) and red cell enzymes (PGM, $A c P$, EsD and F13B) were assayed and compared to determine the probability of dizygosity as described by Lykken [11]. If the a priori diagnosis was $\mathrm{MZ}$, we required one discordant locus to change the diagnosis from $\mathrm{MZ}$ to $\mathrm{DZ}$. To change an a priori diagnosis of $\mathrm{DZ}$ to $\mathrm{MZ}$, we required a probability of dizygosity less than 0.01 . The overall misclassification rate for diagnoses made on the basis of physical similarity was $8 \%$, and did not differ by rearing group. Eleven percent of the pairs (16 of 142) originally diagnosed as $M Z$ differed in at least one marker and were thus re-classified as DZ. Eleven of 210 pairs $(5 \%$ ) initially classified as DZ were identical for all of the markers and had a probability greater than $99 \%$ of being MZ. Of the 17 pairs unclassifiable by the physical similarity criteria $(\mathrm{XZ})$, the serological diagnosis was $\mathrm{DZ}$ for 6 and $\mathrm{MZ}$ for 10 . The probability of being MZ was $\mathbf{9 8 \%}$ for one pair initially not classified but identical with respect to 7 markers. We chose to keep this pair classified as $\mathrm{XZ}$.

We tested for the effects of misclassification by first calculating intraclass correlations for height and weight in the IPT sample of pairs as initially diagnosed and then recalculating the correlations after correction in zygosity (Table 5). The correlations differed only slightly (at most 0.02 ). There were no differences in parameter estimates from model-fitting analyses of the data.

Table 5 - Intraclass correlations for height and weight by zygosity classification from questionnaire and from serological results

\begin{tabular}{lccc}
\hline \multirow{2}{*}{ Zygosity diagnosis } & No. pairs ${ }^{a}$ & \multicolumn{2}{c}{ Intraclass correlation } \\
\cline { 3 - 4 } & & Height ${ }^{b}$ & Weight $^{b}$ \\
\hline $\begin{array}{l}\text { Monozygotic } \\
\text { by questionnaire }\end{array}$ & 104 & & \\
by serology & 102 & 0.87 & 0.73 \\
Dizygotic & & 0.85 & 0.72 \\
$\quad$ by questionnaire & 181 & & 0.21 \\
by serology & 183 & 0.51 & 0.23 \\
\hline
\end{tabular}

$a$ The sample is based on pairs participating in IPT1. Excluded from the sample are pairs not classifiable on the basis of questionnaire information (XZs).

$b$ Measured by registered nurses during in-person testing. 
The 368 pairs for which serological diagnoses were available represent $49 \%$ of the total SATSA Q1 sample. One would expect that the changes in zygosity would have even less effect on the analyses of the questionnaire data since the pairs which changed zygosity constitute a smaller proportion of the Q1 sample than of the IPT sample. We reran the genetic model-fitting analyses for neuroticism and extraversion with the corrected zygosity classifications. The parameter estimates from the corrected classification are well within the standard errors of the parameter estimates reported by Pedersen et al [18], which were based on the initial questionnaire diagnoses. Additive genetic variance was initially estimated as $1.28( \pm 0.15)$ for neuroticism. After zygosity diagnoses were corrected, the estimate was $1.34( \pm 0.14)$. The estimates of nonadditive genetic variance for extraversion were $1.48( \pm 0.12)$ and $1.44( \pm 0.13)$ before and after correction, respectively. Similarly, the estimates of heritability based on the corrected diagnoses differ by less than 0.03 from the earlier estimates (from 0.31 initially to 0.34 for neuroticism and from 0.42 to 0.39 for extraversion). Table 1 describing the SATSA sample is based on the corrected zygosities.

The excess among reared-together pairs of fraternal twins compared to identical twins ( $42 \% \mathrm{MZ}, 58 \% \mathrm{DZ})$ conforms to a similar finding for the entire Swedish Twin Registry [6] for which $56.7 \%$ of the twins in the young cohort and $62.3 \%$ in the older cohort are fraternal. In the TRA sample, the overabundance of DZ is slightly greater than that for the registry as a whole (68\% vs $57 \%-62 \%)$. Two possibilities suggest themselves for this excess: either parents were more likely to adopt away fraternal twins, or more identical twins were misclassified as fraternal twins in the TRA sample. The latter explanation is unlikely; $5 \%$ of the TRA and $6 \%$ of the TRT originally diagnosed as DZ were actually MZ. If parents were more likely to adopt away fraternal twins, one would assume that they would do so after some point at which they could distinguish between the twins, ie, notice that they were fraternal. If that were the case, one would expect the proportion of fraternal twins in the TRA sample to increase with increasing age at separation. Indeed, of the pairs separated before their second birthday, $63 \%$ are DZ whereas $77 \%$ of those separated 2-10 years of age are DZ. Presumably, parents were less likely to separate a pair that appeared to be identical than those who appeared to be fraternal after the second birthday.

\section{OVERVIEW OF RESULTS}

\section{Q1}

The univariate analyses of Q1 have been focused on three phenotypic domains: personality, health and health related behaviors, and measures of the environment. Other analyses involved exploration of cross-sectional age differences in heritability for the first two domains. Multivariate analyses exploring the genetic and environmental influences on covariation within and among domains are underway, as are analyses of the Q2 data, Q1-Q2 longitudinal relationships, and the IPT data.

Personality. Most of the univariate results for the personality domain have been summarized by McClearn et al [12]. The proportions of phenotypic variance attributable to 
genetic and environmental sources calculated from maximum-likelihood model-fitting analyses utilizing both zygosity and rearing condition are reported in Table 6 . The broad-sense heritabilities, which include additive $(\mathrm{Ga})$ and nonadditive $(\mathrm{Gd})$ genetic variance, average 0.30 and range from 0.12 to 0.45 except for the Locus of Control subscale "Luck", which shows no trace of genetic influence $[2,15,16,18,23]$. It is noteworthy that these personality variables, particularly those related to Extraversion, often suggest evidence for non-additive genetic variance. Data from twins reared apart can help in disentangling violations of the unequal environments assumption for twins reared together from nonadditive genetic variance. Such comparisons in SATSA suggest the existence of an assimilation effect for MZT that inflates their similarity and is misread as nonadditive genetic variance; however, some nonadditive genetic variance is suggested even for twins reared apart for extraversion [19]. Nonadditive genetic variance and MZT assimilation effects are also likely to be responsible for estimates of heritability from studies of twins reared together that exceed estimates from adoption studies of first-degree relatives, who scarcely share nonadditive genetic variance.

Of the environmental influence, almost all is of the nonshared variety. Exceptions to this generality are Luck, Agreeableness, Hostility, and Lack of Assertiveness, for which significant proportions of total variation attributable to shared rearing environments are 31, 21, 20, and 19 percent, respectively. Shared rearing environments (Es) account for $0-13 \%$ (average $6 \%$ ) for the remaining 21 variables. It is interesting to note that models including forms of correlated environments other than shared rearing environment can be fit to the data for Neuroticism, Hostility, and Luck. The correlated environments parameter $(\mathrm{Ec})$ in these models account for up to $21 \%$ of the variation.

Age differences in heritabilities have been tested for all of the personality scales. Only two of the measures, the Mental Health scale of Depression and the Life Direction subscale of Locus of Control, show differences in heritability across four age bands (< $50,50-59,60-69, \geq 70$ years). The latter measure shows a decline in heritability in the oldest age band and the former shows a variable pattern.

Health and health-related behaviors. The analyses of the measures of physical health and health-related behaviors were structured somewhat differently from those for the personality domain. Age and/or gender effects in total variation were expected for the health domain and hence analyses were performed to explore the nature of these differences. For the two self- reported measures of physical health, SUMILL (a general health scale which indexes chronic illness) and the self-rated health scale (SRHEALTH), variability increases in older age groups [8,9]. Most of the increase in variation for SUMILL up to age 70 is accounted for by an increase in genetic sources of variation. However, it appears that correlated environmental influences, such as adult contact with one's cotwin, become important after 70 years of age. In contrast, the increase in individual differences for SRHEALTH is primarily explained by nonshared environmental influences.

Quantitative genetic analyses of the body mass index were performed separately for men and for women. Although the broad-sense heritabilities were quite similar for the two genders ( $74 \%$ for men and $69 \%$ for women), model-fitting analyses suggested that genetic effects may be operating in a largely nonadditive manner for men, whereas among women additive and nonadditive genetic variance are of equal importance [26]. 
Table 6 - Summary of proportions of variance attributable to genetic and environmental sources for personality measures in SATSA

\begin{tabular}{|c|c|c|c|c|c|c|c|c|}
\hline \multirow{2}{*}{ Variable } & \multirow{2}{*}{ Reference } & \multicolumn{2}{|c|}{ Genetic } & \multicolumn{2}{|c|}{ Environmental } & \multirow{2}{*}{$x^{2}$} & \multirow{2}{*}{$\mathrm{df}$} & \multirow{2}{*}{$\mathrm{p}$} \\
\hline & & $\mathrm{G}_{\mathrm{a}}$ & $\mathrm{G}_{\mathrm{d}}$ & $\mathrm{E}_{\mathrm{s}}$ & $E_{n}$ & & & \\
\hline \multicolumn{9}{|l|}{ Eysenck } \\
\hline Neuroticism & 18 & .31 & .00 & .10 & .58 & 8.10 & 4 & .088 \\
\hline Extraversion & 18 & .00 & .41 & .07 & .52 & 7.82 & 4 & .099 \\
\hline \multicolumn{9}{|l|}{$E A S$} \\
\hline E-distress & 23 & .36 & .03 & .06 & .55 & 5.7 & 4 & .26 \\
\hline E-fear & 23 & .00 & .39 & .04 & .57 & 4.2 & 4 & .39 \\
\hline E-anger & 23 & .13 & .15 & .12 & .60 & 2.9 & 4 & .57 \\
\hline Activity & 23 & .00 & .23 & .12 & .65 & 1.5 & 4 & .82 \\
\hline Sociability & 23 & 24 & .00 & .13 & .64 & 10.2 & 4 & .04 \\
\hline \multicolumn{9}{|l|}{$K S P$} \\
\hline Impulsivity & 18 & .02 & .43 & .00 & .55 & 2.89 & 4 & .576 \\
\hline Monotony & 18 & .23 & .00 & .05 & .72 & 3.38 & 4 & .496 \\
\hline Avoidance & & & & & & & & \\
\hline $\begin{array}{l}\text { Lack of } \\
\text { assertiveness }\end{array}$ & 16 & .00 & .12 & .19 & .69 & 3.14 & 4 & .679 \\
\hline \multicolumn{9}{|l|}{ Type- $A$} \\
\hline Framingham & 16 & .27 & .00 & .11 & .62 & 1.72 & 4 & .778 \\
\hline Pressure & 16 & .28 & .00 & .12 & .60 & 1.84 & 4 & .765 \\
\hline Hard-driving & 16 & .00 & .43 & .00 & .57 & 4.63 & 4 & .327 \\
\hline Ambitious & 16 & .00 & .37 & .00 & .63 & 3.62 & 4 & .46 \\
\hline \multicolumn{9}{|l|}{ Locus of Control } \\
\hline Luck & 15 & .00 & .00 & .31 & .69 & 7.28 & 4 & .296 \\
\hline Life direction & 15 & .28 & .00 & .00 & .72 & 8.35 & 4 & .213 \\
\hline Misfortunes & 15 & .35 & .00 & .00 & .65 & 4.03 & 4 & .673 \\
\hline \multicolumn{9}{|l|}{$N E O$} \\
\hline Openness & 2 & .38 & .02 & .06 & .54 & 10.30 & 4 & .07 \\
\hline Agreeableness & 2 & - & .12 & .21 & .67 & 1.05 & 5 & .90 \\
\hline Conscientiousness & 2 & - & .29 & .11 & .60 & 2.15 & 5 & .71 \\
\hline \multicolumn{9}{|c|}{ OARS Mental Health } \\
\hline Depression & 12 & .30 & .00 & .00 & .70 & 2.43 & 4 & .787 \\
\hline Alienation & 12 & .27 & .00 & .00 & .73 & 29.78 & 4 & .000 \\
\hline Somatic & 12 & .30 & .00 & .00 & .70 & 30.77 & 4 & .000 \\
\hline \multicolumn{9}{|l|}{ Other } \\
\hline Hostility & 16 & .20 & .00 & .20 & .59 & 6.48 & 4 & .166 \\
\hline Life satisfaction & 12 & .32 & .00 & .11 & .56 & 11.61 & 4 & .041 \\
\hline
\end{tabular}

Note: $\mathrm{G}_{\mathrm{a}}=$ Additive genetic variance, $\mathrm{G}_{\mathrm{d}}=$ nonadditive gentic variance, $\mathrm{E}_{\mathrm{s}}=$ Shared rearing environmental variance, $\mathrm{E}_{\mathrm{n}}=$ Nonshared environmental variance.

Reference refers to the number of the reference in which the results have been published. 
The analyses also indicated that shared environments (early rearing or correlated adult environments) did not contribute significantly to similarity in body mass index.

Genetic influences on measures of the environment. The SATSA design is well suited for studying the possibility of genetic influence on measures that are apparently measures of the environment. In Q1a, the Moos Family Environment Scale [21,22] was included and modified to be descriptive of the circumstances in the rearing home. The FES describing the current family situation, a life-events scale [20], and measures of social support [4] were included in Q1b. These ostensible measures of the environment, which may reflect both perceptions of or actual environmental circumstances, were submitted to the same model-fitting procedures as the other phenotypic domains.

Genetic influence was significant for each of the 8 FES scales representing perceptions of the childhood family environment except Control [21] and accounted for $26 \%$ of the variation on average. The parameter for shared rearing environments was also significant, accounting for $10 \%-31 \%$ of the total variation. A selective-placement parameter which reflects twin similarity not attributable to genetic factors or shared rearing environment, was significant for the Cohesion and Active scales. These results clearly indicate that retrospective perceptions of the environment are, to some degree, genetically influenced.

The presence of a significant effect of shared rearing environments is not surprising, since the TRT were reared in the same homes. What is surprising, however, is that this parameter was not more important, ie, that TRT were not more similar in their perceptions of their rearing home.

A related analysis of perceptions of current family environment [22] gave similar results; about $25 \%$ of the variance was attributable to genetic factors. Of the eight FES scales, Cultural-Intellectual Orientation showed the most genetic influence ( $40 \%$ heritability) and Achievement Orientation showed the least (12\% heritability). Rearing environment had little effect on adults' ratings of their family environment.

Other measures of the environment subjected to quantitative genetic analysis were Life Events [20] and Social Support [4]. Life events which are considered to be under the control of the individual showed significant genetic influence as did perceived adequacy of social support. In contrast, genetic variance was small or nonsignificant for reporting of events in one's life over which one has no direct control and for the quantity of supportive relationships.

Genotype-environment interaction. Although the possibility of gene-environment interactions is a prominent feature of quantitative genetic theory, few results have documented specific empirical examples in human research. Bergeman et al [3] found evidence for 11 significant interactions between personality and environmental variables after main effects (of genotype and environment) were statistically removed.

Several types of interaction were described; for example, individuals with a genotype predisposing for high extraversion scores (so classified on the basis of their twin's score) tend to express the trait regardless of the level of "control" or "organization" in their rearing environment. For individuals with a genotype predisposing for low extraversion, a (retrospectively perceived) family environment high in "control" or "organization" results in lower extraversion scores. 
Effects of age at and degree of separation. For the majority of the measures from Q1a and Q1b, analyses comparing twins reared together (TRT) and twins reared apart (TRA) provide little evidence of shared rearing environment, in that TRT are no more similar later in life than TRA [12]. However, strictly speaking, this method assumes that TRA have been reared in uncorrelated environments and have had no contact with each other. In fact, there is considerable variation in the extent to which the TRA have been separated; about $50 \%$ were separated during their first year, $82 \%$ by their fifth birthday, and the rest by their eleventh birthday. Some individuals have never met their twin; members of other pairs met as young adults; others attended the same schools as their twin. This variation in age at separation and degree of separation provided the opportunity for a more fine-grained analysis of the extent to which varied degrees of shared rearing environment is of importance for measures in SATSA [17]. For example, multiple regression analyses indicated that degree of separation relates to spirits and total alcohol consumption in the expected direction; twins with more contact are more similar and thus the shared rearing environment is of importance. For personality measures, the greatest number of significant effects were for number of years separated. However, the effects were small and significant primarily for identical twins and provide additional support for the conclusion that environmental factors important to personality development are those experienced differentially by children from the same family, so-called non-shared environmental influences.

\section{Ongoing and Future Analyses}

SATSA is the first twin study of gerontology since Kallmann's study in the 1940s. Developmentalists with a life-span perspective recognize that the behavioral genetics story of individual differences in functioning later in life could be very different than earlier in the life course. For example, it is reasonable to predict that, as time goes by, life events increasingly account for variance in behavior and perhaps overwhelm genetic differences. However, SATSA results to date show significant and substantial genetic influence in the last half of the lifespan.

The focus of current analyses are the IPT1 data, multivariate analyses of the covariance between domains, and longitudinal analyses of change and continuity between Q1 and Q2. The IPT provides measures especially important in aging such as functional capacity, measures of physical performance, neurological status, general health, cardiovascular health, and cognitive abilities. Multivariate analyses will allow us to apply the power of the SATSA design to the covariance among domains rather than to the variance of each measure considered individually. For example, to what extent are associations between biomedical measures and behavioral measures mediated genetically? We are especially interested in the etiology of associations between cognition and health.

The most expensive and time-consuming aspect of SATSA is its longitudinal followups. However, this is also the most exciting feature of the project: longitudinal data are the sine qua non of analyses of age changes and continuities, which are the key issues of aging. We have begun analyses of the three-year follow-up data from Q1 to Q2. However, our sights are on the turn of the century when five, three-year waves of data 
will be available. These data will make it possible to analyse genetic contributions to age changes and continuities during the course of a decade and a half in the later lives of the SATSA twins.

Acknowledgment: SATSA has been supported by grants from the National Institute of Aging (AG04563) and the MacArthur Foundation Research Network on Successful Aging.

\section{REFERENCES}

1. Berg S (1980): Psychological functioning in 70- and 75- year old people: A study in an industrialized city. Acta Psych Scand Suppl 288, 62:1-43.

2. Bergeman CS, Chipuer HM, Plomin R, Pedersen NL, McClearn GE, Nesselroade JR, Costa P, McCrae RR (1989): Genetic and environmental effects on openness to experience, agreeableness, and conscientiousness: An adoption/twin study. Submitted.

3. Bergeman CS, Plomin R, McClearn GE, Pedersen NL, Friberg L (1988): Genotypeenvironment interaction in temperament development: Identical twins reared apart. Psych and Aging 3:399-406.

4. Bergeman CS, Plomin R, Pedersen NL, McClearn GE, Nesselroade JR (1990): Genetic and environmental influences on social support: The Swedish Adoption/Twin Study of Aging (SATSA). J Gerontol Psychol Sci 45:101-106.

5. Bouchard TJJr (1984): Twins reared apart and together: What they tell us about human diversity. In Fox S (ed), The Chemical and Biological Bases of Individuality. New York: Plenum, pp 147-178.

6. Cederlof R, Lorich U (1978): The Swedish Twin Registry. In Nance WE, Allen G, Parisi P (eds), Twin Reserach: Part C. Biology and Epidemiology. New York: Alan R Liss, pp 189-195.

7. Farber SL (1981): Identical Twins Reared Apart: A Reanalysis. New York: Basic Books.

8. Harris JR (1988): The Etiology of Individual Differences in Health and Anthropometric Measures: A Developmental Study of Adult Twins. Unpublished Doctoral Dissertation. Pennsylvania State University.

9. Harris JR, Pedersen NL, McClearn GE, Plomin R, Nesselroade JR (1989): Age differences in genetic and environmental influences for health from The Swedish Adoption/Twin Study of Aging (in press).

10. Langinvainio H, Koskenvuo M, Kaprio J, Sistonen P (1984): Finnish twins reared apart II, Validation of zygosity, environmental dissimilarity and weight and height. Acta Genet Med Gemellol 33:251-258.

11. Lykken DT (1978): The diagnosis of zygosity in twins. Behav Gen 8:437-474.

12. McClearn GE, Pedersen NL, Plomin R, Nesselroade JR, Friberg L, DeFaire U (1989): Age and gender effects for individual differences in behavioral aging: The Swedish Adoption/Twin Study of Aging. Manuscript report of the Center for Developmental and Health Genetics, Pennsylvania State University.

13. Nesselroade JR, Pedersen N, McClearn GE, Plomin R, Bergeman CS (1988): Factorial and criterion validities of telephone-assessed cognitive ability measures: Age and gender comparisons in adult twins. Res Aging 10:220-234.

14. Pedersen NL, Floderus-Myrhed B, Friberg L, McClearn GE, Plomin R (1984): Swedish early separated twins: Characterization and identification. Acta Gen Med Gemell 33:243-251.

15. Pedersen NL, Gatz M, Plomin R, Nesselroade R, McClearn GE (1989): Individual differences in locus of control during the second half of the lifespan for identical and fraternal twins reared apart and reared together. J Geron: Psych Sci 44:100-105. 
16. Pedersen NL, Lichtenstein P, Plomin R, DeFaire U, McClearn GE, Matthews KA (1989): Genetic and environmental influences for Type A-like and related traits: A study of twins reared together and twins reared apart. Psychosom Med 51:428-440.

17. Pedersen NL, McClearn GE, Plomin R, Nesselroade JR (1991): Effects of early rearing environment of twin similarity in the last half of the life span. (Under review).

18. Pedersen NL, Plomin R, McClearn GE, Friberg L (1988): Neuroticism, extraversion and related traits in adult twins reared apart and reared together. J Pers Soc Psych 55:950-957.

19. Plomin R, Chipuer HM, Loehlin JC (1990): Behavioral genetics and personality. In Pervin LA (ed), Handbook of Personality Theory and Research. New York: Guilford Press (in press).

20. Plomin R, lichtenstein P, Pedersen NL, McClearn GE, Nesselroade JR (1989): Genetic influence on life events during the last half of the life span. Psych and Aging 5:25-30.

21. Plomin R, McClearn GE, Pedersen NL, Nesselroade JR, Bergeman CS (1988): Genetic influence on childhood family environment perceived retrospectively from the last half of the life span. Dev Psych 24:738-745.

22. Plomin R, McClearn GE, Pedersen NL, Nesselroade JR, Bergeman CS (1989): Genetic influence on adults' perceptions of their family environment. J Marr Fam 51:791-803.

23. Plomin R, Pedersen NL, McClearn GE, Nesselroade J, Bergeman CS (1988): AES temperaments during the last half of the life span: Twins reared apart and twins reared together. Psych and Aging 3:43-50.

24. Reff ME, Schneider EL (eds) (1982): Biological Markers of Aging. DHHS Publ No. 82-2221. Washingyon DC: US Government Printing Office.

25. Schalling DS, Pedersen NL, Bartfai A (1989): A twin study of biopsychological vulnerability. In preparation.

26. Stunkard AJ, Harris JR, Pedersen NL, McClearn GE (1990): A separated twin study of the body mass index. N Eng J Med. 322:1483-1487.

Correspondence: Dr. Nancy Pedersen, Department of Environmental Hygiene, Karolinska Institute, P.O. Box 60400, S-104 01 Stockholm, Sweden. 